\title{
Influência de doses de nitrogênio na produtividade e qualidade do melão Cantalupensis sob ambiente protegido
}

\author{
Roberto Cleiton F de Queiroga ${ }^{1}$; Mário Puiatti'; Paulo Cezar R Fontes ${ }^{1}$; Paulo Roberto Cecon²; Fernando \\ Luiz Finger ${ }^{1}$ \\ ${ }^{1 ; 2}$ UFV, Deptos. Fitotecnia e Informática. 36570-000 Viçosa-MG; robertocleiton@ @otmail.com
}

\begin{abstract}
RESUMO
O N promove alterações morfo-fisiológicas modificando o crescimento e o desenvolvimento das plantas, razões pelas quais se torna importante o manejo adequado deste nutriente, sobretudo em ambiente protegido. Foram avaliadas a produtividade e qualidade de frutos dos meloeiros Fleuron e Torreon (grupo Cantalupensis), submetidos a cinco doses de $\mathrm{N}\left(0 ; 90 ; 180 ; 360\right.$ e $\left.540 \mathrm{~kg} \mathrm{ha}^{-1}\right)$. Utilizou-se o esquema de parcelas subdivididas, delineamento experimental de blocos casualizados, com quatro repetições. Avaliou-se o número de folhas, área foliar por planta, características de produção e qualidade dos frutos. A 'Torreon', comparada com a 'Fleuron', apresentou maior número de folhas, área foliar, massa média de fruto, produtividade total e comercial, comprimento e índice de formato e menor diâmetro de frutos. Aumento da dose de $\mathrm{N}$ promoveu incremento linear na espessura de mesocarpo, teor de sólidos solúveis totais e acidez titulável e decréscimo linear para índice de maturação. Valores máximos estimados de 46,6 folhas planta ${ }^{-1}, 9.364$ $\mathrm{cm}^{2}$ planta $^{-1}$ de área foliar, 1,3 frutos planta ${ }^{-1}, 1.083 \mathrm{~g} \mathrm{fruto}^{-1}, 46,50 \mathrm{e}$ $43,73 \mathrm{t} \mathrm{ha}^{-1}$ de produtividade total e comercial, e frutos com $15,2 \mathrm{~cm}$ de comprimento, $13,3 \mathrm{~cm}$ de diâmetro, $6,1 \mathrm{~cm}$ de diâmetro da cavidade e 1,15 no índice de formato, foram obtidos, respectivamente, com as doses de $\mathrm{N}$ de 337, 337, 305, 339, 287, 310, 364, 373, 322 e $359 \mathrm{~kg} \mathrm{ha}^{-1}$.
\end{abstract}

Palavras-chave: Cucumis melo, nutrição mineral, rendimento, sólidos solúveis totais.

\begin{abstract}
Yield and quality of muskmelon fruits cultivated in greenhouse with doses of nitrogen

Nitrogen promotes morfo-physiologic changes modifying plant growth and development. So, the appropriate management of this nutrient is important, especially under protected environment. The fruit yield and quality of two melon cultivars of the Cantalupensis group (Fleuron and Torreon) were evaluated using five $\mathrm{N}$ doses $(0$; 90; 180; 360 and $540 \mathrm{~kg} \mathrm{ha}^{-1}$ ). A split splot scheme, in randomized blocks design, with four replications was used. The number and foliar area, fruit yield and quality were determined. 'Torreon', compared to 'Fleuron', presented higher leaf number, leaf area, fruit weight, total and commercial yield, fruit length and format index and also presented smaller fruit diameter. Increasing $\mathrm{N}$ rates promoted linear increment in the mesocarp thickness, total soluble solids and titratable acidity and lineal decrease in maturation index. The maximum estimated values were 46.6 leaves plant ${ }^{-1}, 9364 \mathrm{~cm}^{2}$ plant $^{-1}$ leaf area, 1.3 fruits plant ${ }^{-1}, 1083 \mathrm{~g}_{\text {fruit }}^{-1}, 46.50$ and $43.73 \mathrm{t} \mathrm{ha}^{-1}$ of total and commercial yield; $15.2 \mathrm{~cm}$ of length, $13.3 \mathrm{~cm}$ of diameter, $6.1 \mathrm{~cm}$ of cavity diameter and 1.15 in the index of fruits format. These values were obtained, respectively, with $\mathrm{N}$ rates of: $337,337,305,339$, $287,310,364,373,322$ and $359 \mathrm{~kg} \mathrm{ha}^{-1}$.
\end{abstract}

Keywords: Cucumis melo, mineral nutrition, yield, total soluble solids.

(Recebido para publicação em 23 de março de 2007; aceito em 29 de novembro de 2007)

$\mathrm{O}$ meloeiro, sobretudo cultivares dos tipos Cantaloupe e Charentais (Cucumis melo L. grupo Cantalupensis), tem sido pouco cultivado na região $\mathrm{Su}-$ deste do Brasil devido às condições climáticas desfavoráveis na maior parte do ano. Nesta região, seu cultivo é mais indicado no verão, em função da elevação da temperatura e da radiação solar. Todavia, o elevado índice pluviométrico nesse período dificulta os tratos culturais, contribui para o aparecimento de pragas e doenças, que causam desfolha das plantas, resultando em baixa produtividade de frutos, de tamanho pequeno, pobremente reticulados, queimados e com baixos teores de açúcares, portanto, de baixa qualidade e valor comercial (Coelho \& Fontes, 2005). Como forma de contornar esses problemas, recomenda-se o cultivo do meloeiro em ambiente protegido o qual, além de manter a temperatura mais adequada para a cultura, protege as plantas da chuva, evitando doenças e seus reflexos negativos na produção. Todavia, são de fundamental importância as pesquisas para atender a demanda por informações técnicas sobre o manejo da cultura, tendo a nutrição nitrogenada importante destaque por estar associada aos aspectos quantitativos e qualitativos da produção.

$\mathrm{O} \mathrm{N}$ promove modificações morfofisiológicas na planta, estando relacionado com a fotossíntese, desenvolvimento e atividades das raízes, absorção iônica de nutrientes, crescimento e diferenciação celular (Carmello, 1999). Além de ser um dos nutrientes absorvi- dos em maior quantidade, exerce influência no crescimento e desenvolvimento tendo efeito direto nas relações fonte-dreno, por alterar a distribuição de assimilados entre a parte vegetativa e reprodutiva (Huett \& Dettmann, 1991).

A resposta do meloeiro ao $\mathrm{N}$ depende da dose aplicada, sendo comum haver indicações variando de 75 a $200 \mathrm{~kg}$ ha ${ }^{-1}$ de N (Buzetti et al., 1993; Pinto et al., 1995; Faria et al., 2000). Todavia, em ambiente protegido, é comum a aplicação de doses excessivas de $\mathrm{N}$, resultando em crescimento vegetativo excessivo e redução da produção comercial de frutos (Coelho et al., 2003).

No cultivo do meloeiro em ambiente protegido e no solo, Coelho et al. (2003), obtiveram produção comercial máxima de frutos com a dose de $312 \mathrm{~kg}$ 
ha ${ }^{-1}$ de $\mathrm{N}$; além disso, o aumento da dose de $\mathrm{N}$ proporcionou melhorias nas características físicas de frutos, sem no entanto, alterar o teor de sólidos solúveis, que foi de $9^{\circ}$ Brix.

Em hidroponia, Purqueiro et al. (2003, 2005) observaram que a dose de $80 \mathrm{mg} \mathrm{L}^{-1}$ de N na solução nutritiva proporcionou maior produção de frutos no meloeiro $\left(2,474 \mathrm{~g}_{\text {planta }}{ }^{-1}\right)$; todavia ocorreu redução na massa média e produtividade comercial com o incremento da concentração do N. Além disso, observaram que o aumento da concentração de $\mathrm{N}$ na solução nutritiva acima de $80 \mathrm{mg} \mathrm{L}^{-1}$, embora não tenha causado nenhum efeito sobre o teor de sólidos solúveis totais, proporcionou aumento na acidez total titulável, redução no comprimento, diâmetro de fruto e espessura do mesocarpo.

Em razão da importância do manejo adequado do $\mathrm{N}$, avaliou-se o efeito de doses de $\mathrm{N}$ na produtividade e qualidade das cultivares de meloeiro Fleuron e Torreon do grupo Cantalupensis, cultivado em ambiente protegido.

\section{MATERIAL E MÉTODOS}

$\mathrm{O}$ experimento foi conduzido em casa de vegetação da UFV, de 26/11/04 a 06/03/05. O solo da área experimental é classificado como ARGISSOLO VERMELHO AMARELO Câmbico (Embrapa, 1999) e apresentou, na camada de 0-20 cm de profundidade, os seguintes atributos: $5,2\left(\mathrm{pH}\right.$ em $\left.\mathrm{H}_{2} \mathrm{O}\right)$; $62,3(\mathrm{P})$ e $163,0(\mathrm{~K}) \mathrm{mg} \mathrm{dm}^{-3} ; 3,4\left(\mathrm{Ca}^{2+}\right)$, $0,7\left(\mathrm{Mg}^{2+}\right), 0,0\left(\mathrm{Al}^{3+}\right)$ e 4,6 $(\mathrm{H}+\mathrm{Al})$ cmol dm ${ }^{-3}$; 15,1 (Zn), 66,1 (Fe), 70,8 $(\mathrm{Mn}), 3,0(\mathrm{Cu})$ e $0,84(\mathrm{~B}) \mathrm{mg} \mathrm{dm}^{-3}$, respectivamente. Durante o período experimental, a temperatura e a umidade relativa do ar no interior da casa de vegetação foram registradas por termohigrômetro digital (modelo HT210), colocado à altura do dossel das plantas. As médias de temperaturas máxima e mínima corresponderam a 36,7 e $18,3^{\circ} \mathrm{C}$ e de umidade relativa do ar de 95,8 e $49,5 \%$, respectivamente.

Utilizou-se o esquema de parcelas subdivididas, no delineamento experimental blocos ao acaso, com quatro repetições. Nas parcelas foram aplicadas cinco doses de N $(0 ; 90 ; 180 ; 360$ e 540 $\mathrm{kg} \mathrm{ha} \mathrm{h}^{-1}$ ), via fertirrigação, na forma de uréia e, nas subparcelas, as cultivares de meloeiro Fleuron e Torreon. A unidade experimental foi constituída de três fileiras de 3,6 m de comprimento, espaçadas de 1,0 x 0,3 m, contendo 36 plantas. Considerou-se, como útil, as 10 plantas centrais de cada fileira central. As cultivares utilizadas são do grupo Cantalupensis, sendo a ‘Torreon' do tipo Cantaloupe e a 'Fleuron' do tipo Charentais. De acordo com as empresas produtoras das sementes, ambas apresentam ciclo precoce, frutos com 1,0 kg de massa média, pequena cavidade de sementes, polpa espessa, casca bastante rendilhada ('Torreon') e altos teores de açúcares.

A casa de vegetação, tipo capela, com largura de 9,0 m, comprimento de $40 \mathrm{~m}$, altura do pé direito e do vão central de 3,0 e $3,8 \mathrm{~m}$, respectivamente, foi coberta com filme de polietileno de baixa densidade, aditivado, de $0,15 \mathrm{~mm}$ de espessura, sendo as frontais e laterais fechadas até a metade de suas alturas.

Durante 30 dias, cerca de 60 dias anterior ao plantio, promoveu-se inundação da área visando-se a eliminação do excesso de sais, principalmente dos nitrogenados, via drenagem. A seguir, corrigiu-se o $\mathrm{pH}$ do solo utilizando-se 2 t ha ${ }^{-1}$ de calcário dolomítico, elevando a saturação de bases para 70\%. Uma semana antes do plantio, procedeu-se a adubação de pré-plantio, de acordo com a análise do solo e recomendações para a cultura (Ribeiro et al., 1999). No sulco de plantio, aplicou-se $\left(\mathrm{kg} \mathrm{ha}^{-1}\right): 300$ de $\mathrm{P}_{2} \mathrm{O}_{5}$, na forma de superfosfato simples; 200 de sulfato de magnésio; 5 de bórax; 5 de sulfato de zinco e 0,5 de molibdato de amônio. Também, em préplantio, foram aplicados $10 \%$ da dose total de $\mathrm{K}_{2} \mathrm{O}\left(15 \mathrm{~kg} \mathrm{ha}^{-1}\right)$ e $10 \%$ da dose de $\mathrm{N}$, de acordo com a dose de cada tratamento. O restante do $\mathrm{K}$ e do $\mathrm{N}$ foi aplicado via fertirrigação, semanalmente, iniciando-se sete dias após o transplante das mudas. Em cada fertirrigação foram aplicados, respectivamente, os nutrientes: $1^{\mathrm{a}}=5 \%$ de $\mathrm{N}$ e $7 \%$ de $\mathrm{K}_{2} \mathrm{O} ; 2^{\mathrm{a}}$ $=8 \%$ de $\mathrm{N}$ e $10 \%$ de $\mathrm{K}_{2} \mathrm{O} ; 3^{\mathrm{a}}=10 \%$ de $\mathrm{Ne} 8 \%$ de $\mathrm{K}_{2} \mathrm{O} ; 4^{\mathrm{a}}, 5^{\mathrm{a}}$ e $6^{\mathrm{a}}=20 \%$ de $\mathrm{Ne}$ $18 \%$ de $\mathrm{K}_{2} \mathrm{O} ; 7^{\mathrm{a}}=7 \%$ de $\mathrm{N}$ e $7 \%$ de $\mathrm{K}_{2} \mathrm{O} ; 8^{\mathrm{a}}$ e $9^{\mathrm{a}}=5 \%$ de $\mathrm{N}$ e $7 \%$ de $\mathrm{K}_{2} \mathrm{O}$.

A semeadura foi realizada em 26/11/ 04, em bandejas de poliestireno de 128 células, utilizando-se substrato agrícola comercial; o transplante ocorreu em 13/12/04, quando as mudas apresentavam a segunda folha completamente expandida. Na irrigação, os gotejadores foram espaçados de $0,30 \mathrm{~m}$, com vazão de 1,20 $\mathrm{L} \mathrm{h}^{-1}$ sendo a necessidade de água a aplicar, monitorada com tensiômetros instalados a $10 \mathrm{~cm}$ de profundidade. As irrigações foram feitas quando a média das leituras dos tensiômetros estavam próximas ou superiores à tensão crítica do meloeiro (30$50 \mathrm{Kpa}$ ) (Embrapa, 2004).

As plantas foram conduzidas, verticalmente, em haste única, com uso de fitilhos fixados em bambu colocado na horizontal a $1,80 \mathrm{~m}$ de altura. Procedeuse à poda da haste principal ("capação") a 1,80 $\mathrm{m}$ do solo. Foi permitido, no máximo, dois frutos por planta, localizados acima do $8^{0}$ nó, com raleio de frutos, quando necessário, e podas constantes de ramificações laterais. No ramo em que o fruto foi fixado foi realizada a poda duas folhas após o fruto. Durante o ciclo foram realizadas duas capinas e controle fitossanitário com fungicidas e inseticidas, semanalmente, com aplicações realizadas no final da tarde. Para auxiliar na polinização, foram colocadas duas colméias de abelhas (Apis mellifera) na parte externa da casa de vegetação, durante o período de floração. A colheita iniciou-se em 22/ 02/05, 88 dias após a semeadura, quando os frutos apresentavam a formação da camada de abscisão na região do pedúnculo, indicativo do ponto de colheita dessas cultivares.

Assim que o ápice das plantas atingiu o bambu (1,80 $\mathrm{m}$ de altura), essas foram capadas e avaliou-se, em duas plantas de cada repetição, o número de folhas e a área foliar por planta. Na colheita dos frutos, avaliou-se o número de frutos por planta; massa média de fruto; produtividade total e comercial; espessura do mesocarpo (medido na região equatorial, após seccionar o fruto no sentido longitudinal); diâmetro da cavidade interna (medido no sentido transversal na região equatorial); comprimento (C) e diâmetro (D) de fruto (medidos na região seccionada), e índice de formato do fruto (razão C/D (Lopes, 1982)). Em amostras de fatias 
Tabela 1. Valores médios de características de planta e de produção e qualidade de frutos das cultivares de meloeiros 'Torreon' e 'Fleuron' cultivadas em ambiente protegido em função de doses de nitrogênio (average values of plant and yield characteristics and quality of melon fruits 'Torreon' and 'Fleuron' cultivated in a protected environment, depending on $\mathrm{N}$ doses). Viçosa, UFV, 2006.

\begin{tabular}{|c|c|c|c|c|}
\hline \multirow{2}{*}{ Característica } & \multicolumn{2}{|c|}{ Cultivares } & \multicolumn{2}{|c|}{ CV (\%) } \\
\hline & Fleuron & Torreon & Parcela & Subparcela \\
\hline Número de folhas planta-1 & $40,25^{*} \mathrm{~b}$ & $44,05 \mathrm{a}$ & 14,07 & 10,56 \\
\hline Área foliar (cm2 planta-1 $)$ & $6.199,44 \mathrm{~b}$ & $7.048,26 \mathrm{a}$ & 7,96 & 11,70 \\
\hline Número de frutos/planta & $1,2 \mathrm{a}$ & $1,2 \mathrm{a}$ & 10,73 & 10,95 \\
\hline $\begin{array}{l}\text { Massa média de frutos ( } \mathrm{g} \\
\text { fruto }^{-1} \text { ) }\end{array}$ & $984,4 \mathrm{~b}$ & $1026,1 \mathrm{a}$ & 11,44 & 7,79 \\
\hline Produtividade total $\left(\mathrm{t} \mathrm{ha}{ }^{-1}\right)$ & $39,04 \mathrm{~b}$ & $41,51 \mathrm{a}$ & 10,55 & 10,12 \\
\hline $\begin{array}{l}\text { Produtividade comercial (t } \\
\mathrm{ha}^{-1} \text { ) }\end{array}$ & $34,87 \mathrm{~b}$ & 38,06 a & 10,63 & 10,31 \\
\hline Comprimento de frutos $(\mathrm{cm})$ & $13,8 b$ & $14,8 \mathrm{a}$ & 4,78 & 3,40 \\
\hline Diâmetro de frutos $(\mathrm{cm})$ & $13,0 \mathrm{a}$ & $12,6 b$ & 4,10 & 3,64 \\
\hline Índice de formato & $1,06 \mathrm{~b}$ & $1,17 \mathrm{a}$ & 3,23 & 4,06 \\
\hline $\begin{array}{l}\text { Espessura do mesocarpo } \\
(\mathrm{cm})\end{array}$ & 3,6 a & $3,6 \mathrm{a}$ & 7,29 & 6,53 \\
\hline Diâmetro da cavidade $(\mathrm{cm})$ & $5,8 \mathrm{a}$ & $5,7 \mathrm{a}$ & 8,41 & 8,29 \\
\hline $\begin{array}{l}\text { Sólidos solúveis totais - SST- } \\
\left.\text { ( }{ }^{\circ} \text { Brix }\right)\end{array}$ & 9,4 a & $9,5 \mathrm{a}$ & 8,45 & 6,82 \\
\hline $\begin{array}{l}\text { Acidez total titulável-ATT-(\% } \\
\text { ác. cítrico) }\end{array}$ & 0,081 a & $0,079 a$ & 10,29 & 9,41 \\
\hline $\begin{array}{l}\text { Índice de maturação } \\
\text { (SST/ATT) }\end{array}$ & $117,2 \mathrm{a}$ & 120,9 a & 14,29 & 8,81 \\
\hline
\end{tabular}

*Nas linhas, médias seguidas pela mesma letra não diferem entre sí pelo teste $\mathrm{F}$ ao nível de $5 \%$ de probabilidade (means followed by the same small letter in the line did not differ from each other, $\mathrm{F}$ test, $5 \%$ probability).

retiradas de frutos no sentido longitudinal, e homogeneizadas em liquidificador para a obtenção do suco, determinou-se o teor de sólidos solúveis totais (TSS), a acidez total titulável (ATT) e o índice de maturação (razão TSS/ATT). O TSS foi determinado por meio de refratômetro de mesa, modelo ATAGO $3 \mathrm{~T}$, obtendo-se os valores em $\%$, corrigidos a $20^{\circ} \mathrm{C}$; para ATT, utilizando uma alíquota de $10 \mathrm{~mL}$ de suco, em duplicata, à qual foi adicionado $40 \mathrm{~mL}$ de água destilada e três gotas do indicador fenolftaleína alcoólica a 1\%; em seguida, procedeu-se a titulação com solução de $\mathrm{NaOH} 0,1 \mathrm{~N}$ até o ponto de viragem, com os resultados expressos em \% de ácido cítrico.

Consideraram-se comerciais, frutos firmes, uniformes na cor, com bom rendilhamento de casca, sem deformações, murchamento, rachaduras e sinais de podridão, de ataque de lagartas e de danos mecânicos.

Os dados obtidos foram submetidos à análise de variância. Para o fator qua- de fruto; e reposta linear para espessura de mesocarpo, teor de SST, ATT e índice de maturação (Figura 2).

Dentre os componentes de produtividade, tem-se o número de frutos por planta e a massa de fruto. O número de frutos produzidos por planta não variou entre as cultivares, no entanto a 'Torreon' apresentou frutos com maior massa média resultando, conseqüentemente, em maiores produtividade total e comercial de frutos (Tabela 1). Além do aspecto varietal, a maior produtividade da 'Torreon' pode estar relacionada à maior fonte (folha), pois essa apresentou maior número de folhas e área foliar por planta que a 'Fleuron', o que pode ter proporcionado maior disponibilidade de fotoassimilados para os frutos, já que o número por planta foi limitado. Entretanto, Maruyama et al. (2000), observaram que a maior produtividade da cultivar Bônus $\mathrm{n}^{0} 2$, comparado a 'D.Carlos', foi devida à maior área foliar na floração e na colheita e também ao maior número de frutos por planta. No meloeiro, o fator varietal é importante, pois Higashi et al. (1999), observaram em condições semelhantes de cultivo, que a 'Fuyu A' apresentava maior número de células na região do pericarpo do que a 'Natsu 4', indicando que, o número de divisões celulares após a antese, favorecido pelo adequado suprimento de assimilados, determina o tamanho final do fruto levando a diferenças no rendimento.

Com o aumento da dose de N, obtiveram-se máximos estimados de 46,6 folhas planta-1; área foliar de 9.364,2 $\mathrm{cm}^{2}$ planta $^{-1}, 1,3$ frutos planta ${ }^{-1}, 1083,4 \mathrm{~g}$ fruto $^{-1}, 46,50$ e $43,73 \mathrm{t} \mathrm{ha}^{-1}$ de produtividade total e comercial de frutos, respectivamente, com doses de $\mathrm{N}$ de 337,4; 337,$1 ; 304,8 ; 339,4 ; 287,1$ e $309,7 \mathrm{~kg}$ ha $^{-1}$ (Figura 1). Comparado à testemunha, estas doses elevaram essas características em, respectivamente, 23,5; 23,$1 ; 12,1 ; 20,5 ; 36,2$ e $59,4 \%$.

O efeito da adubação nitrogenada na produção do meloeiro é resultado do aumento do número e massa de fruto, que são características determinantes na produtividade da cultura (Faria, 1990). De acordo com Huett \& Dettmann (1991), o N influencia processos que envolvem crescimento e desenvolvi- 

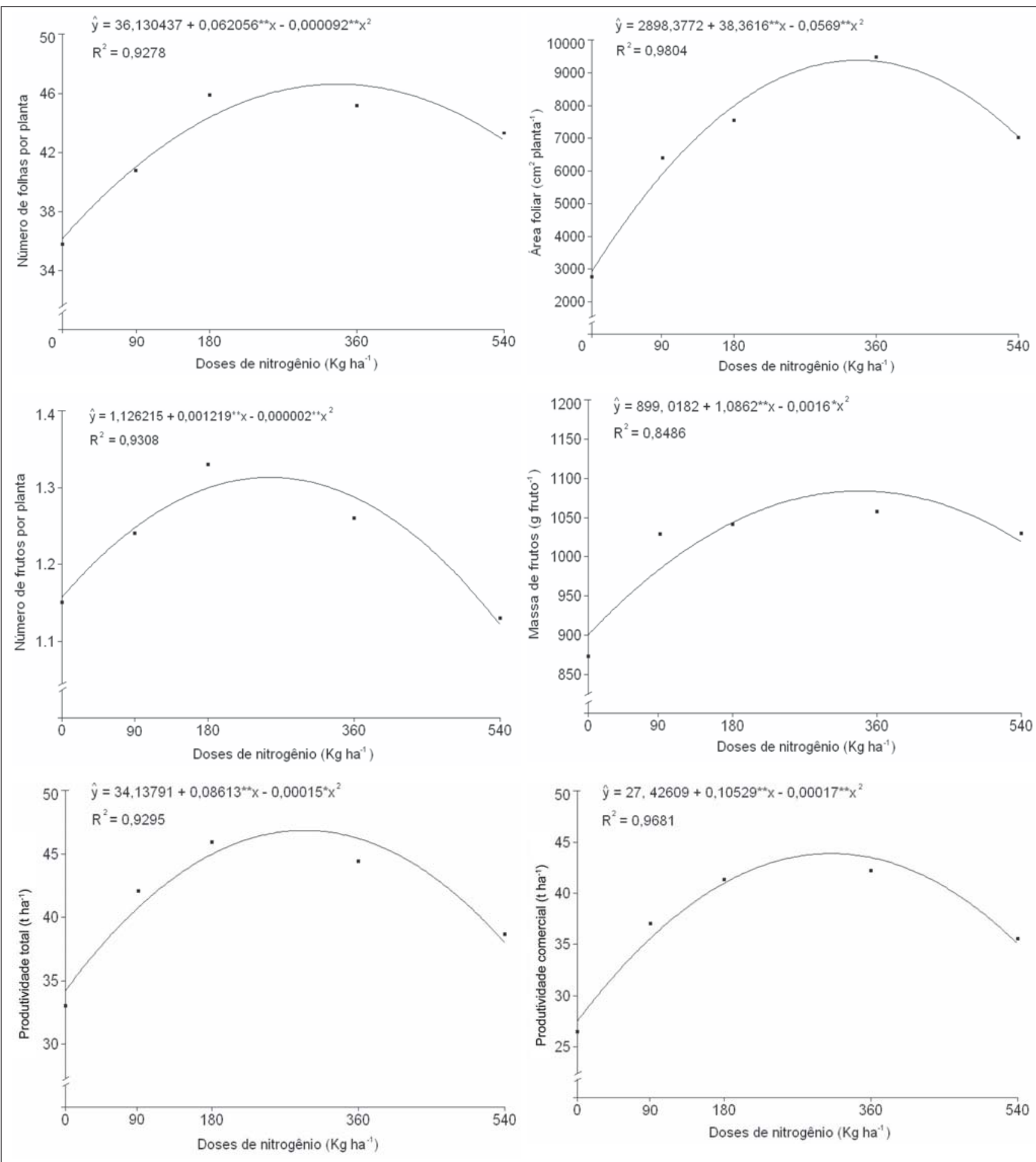

Figura 1. Estimativa de número de folhas, frutos e área foliar por planta, massa média de fruto, produtividade total e comercial de frutos de meloeiros cultivados em ambiente protegido em função de doses de nitrogênio (estimated number of leaves, fruits and foliar área/plant, average fruit mass, total and commercial yield of melons, cultivated in a protected environment, depending on N doses). Viçosa, UFV, 2006. **;*significativo a 1 e $5 \%$ de probabilidade pelo teste $\mathrm{t}(* * ;$ significant through the $\mathrm{t}$ test, 1 and $5 \%$ probability).

mento tendo efeito direto nas relações fonte-dreno, alterando a distribuição de assimilados entre partes vegetativa e reprodutiva. O aumento da dose de $\mathrm{N}$ até determinado limite, proporciona incremento na área foliar da planta
(Nerson et al., 1992); portanto, exerce efeito na produção de fotoassimilados e, conseqüentemente, na produção de frutos. Porém, Purqueiro et al. (2003) não observaram aumento significativo da área foliar com elevação na concen- tração de $\mathrm{N}$ na solução nutritiva, e atribuíram este fato à elevada densidade de plantio (33.333 plantas ha ${ }^{-1}$ ), todavia esta foi igual a utilizada neste trabalho.

Diversos autores (Pinto et al., 1997; Faria et al., 2000; Coelho et al., 2003), 

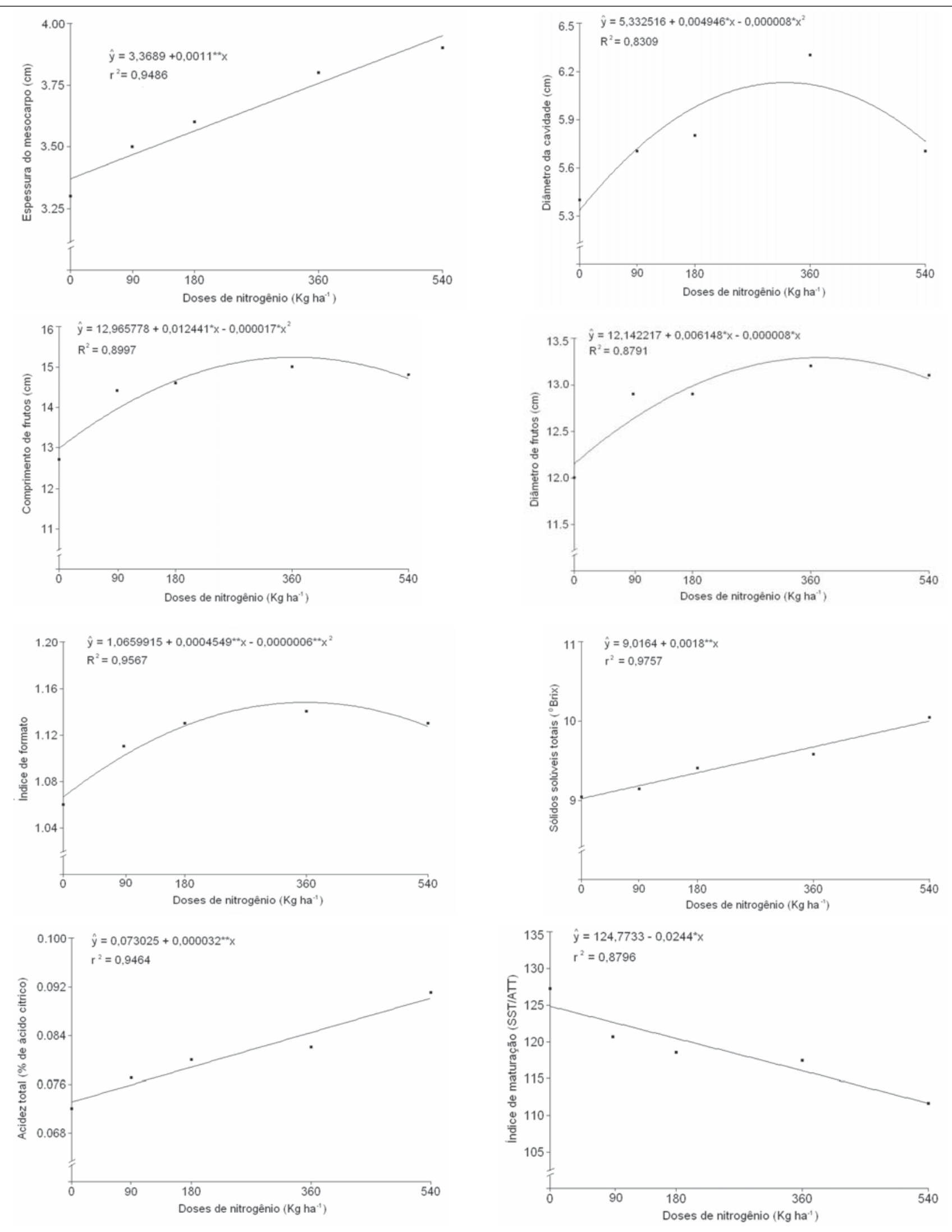

Figura 2. Estimativa da espessura do mesocarpo, diâmetro da cavidade, comprimento e diâmetro de fruto, índice de formato, sólidos solúveis totais, acidez total e índice de maturação de frutos de meloeiros cultivados em ambiente protegido em função de doses de nitrogênio(estimated mesocarp thickness, diameter of the cavity, lenght and diameter of the fruit, format index, total soluble solids, total acidity and maturation index of melon fruits, cultivated in a protected environment, depending on N doses). Viçosa, UFV, 2006.

**;*significativo a 1 e $5 \%$ de probabilidade pelo teste $\mathrm{t}(* * * *$ significant through the $\mathrm{t}$ test, 1 and $5 \%$ probability). 
obtiveram aumento do número e da massa média de fruto e, conseqüentemente, da produtividade, com a elevação das doses de N. Neste trabalho, o efeito favorável na produtividade comercial do meloeiro ocorreu até a dose de $309,7 \mathrm{~kg} \mathrm{ha}^{-1}$ de N. De acordo com Silva et al. (1999), a falta de resposta a doses elevadas de $\mathrm{N}$ pode estar associada à inibição competitiva entre ${\mathrm{o} \mathrm{NH}_{4}^{+}}^{+}$ e absorção de outros cátions, dentre eles $\mathrm{K}^{+}, \mathrm{Ca}^{2+}$ e $\mathrm{Mg}^{2+}$.

A 'Torreon' apresentou frutos com maior comprimento e menor diâmetro em relação à 'Fleuron', resultando em maior índice de formato de frutos (Tabela 1). No meloeiro, o tamanho do fruto é definido pelo número de células do pericarpo, em que esse pode ser afetado por fatores genético e ambiental, especialmente a temperatura, a qual pode influenciar no número de divisões celulares determinando, assim, o tamanho final do fruto (Higashi et al., 1999). Os valores de comprimento e diâmetro dos frutos da 'Fleuron' e 'Torreon' foram maiores que os encontrados por Rizzo \& Braz (2001) no cultivo em solo, Pádua (2001) e Purqueiro \& Cecílio Filho (2005), em hidroponia, em diferentes cultivares de meloeiro. Os frutos da 'Fleuron' apresentaram valor, para o índice de formato, de 1,06 que está numa faixa de transição entre esférico e oblongo; da 'Torreon' foi de 1,17, considerado oblongo (Lopes, 1982). O índice de formato de fruto, em melão, é importante atributo para classificação e padronização, podendo determinar a aceitação e valorização do produto para determinados tipos de mercado e para a definição da embalagem e do arranjo dos frutos no seu interior (Purqueiro \& Cecílio Filho, 2005).

$\mathrm{O}$ índice de formato de fruto e seus componentes (comprimento e diâmetro), apresentaram resposta quadrática ao aumento da dose de N. Valores máximos estimados de 15,2 e 13,3 cm no comprimento e diâmetro de frutos, respectivamente, foram obtidos com as doses de $\mathrm{N}$ de 364,2 e $373,1 \mathrm{~kg} \mathrm{ha}^{-1}$. O índice de formato máximo estimado de 1,15 foi obtido na dose de $\mathrm{N}$ de 359,3 $\mathrm{kg} \mathrm{ha}^{-1}$; portanto, essa dose proporcionou maior crescimento do fruto em comprimento do que em diâmetro (Figura
2). Purqueiro \& Cecílio Filho (2005), obtiveram, no meloeiro Bônus $\mathrm{n}^{0} 2$, dose ótima de $80 \mathrm{mg} \mathrm{L}^{-1}$ de $\mathrm{N}$ na solução nutritiva, a qual proporcionou comprimento e diâmetro máximos de fruto de 13,3 e $11,4 \mathrm{~cm}$, respectivamente. Para Huett \& Dettmann (1991), o N é um dos nutrientes absorvido em maior quantidade, influenciando vários processos, exercendo efeito direto na relação fonte-dreno, alterando a distribuição de assimilados entre a parte vegetativa e reprodutiva. Portanto, o N proporciona incremento na massa vegetativa da planta em termos de área foliar, até determinado limite e, conseqüentemente, pode proporcionar maior produção de assimilados que são destinados aos frutos, promovendo o crescimento desses de acordo com o potencial genético de cada cultivar.

Apesar da maior massa média de frutos da 'Torreon', a espessura do mesocarpo e o diâmetro da cavidade dos frutos não diferiu entre as cultivares (Tabela 1). Todavia, os valores de espessura do mesocarpo dessas cultivares, foram superiores aos obtidos por Pádua (2001) e Rizzo et al. (2001), com diferentes híbridos de meloeiro, e semelhantes $(3,58 \mathrm{~cm})$ aos obtidos por Hecktkeuer et al. (1995) em melão amarelo. A espessura do mesocarpo constitui atributo de qualidade importante por se tratar da parte comestível do fruto e, também, por seu aumento poder levar à redução da cavidade interna do fruto que, por sua vez, também é importante atributo de qualidade de melões rendilhados (Coelho et al., 2003).

$\mathrm{O}$ aumento na dose de $\mathrm{N}$ proporcionou incremento linear na espessura do mesocarpo, passando de 3,4 (controle) para 4,0 cm (dose máxima). Por outro lado, o diâmetro da cavidade dos frutos apresentou resposta quadrática às doses de $\mathrm{N}$, com valor máximo estimado de $6,1 \mathrm{~cm}$ ocorrendo na dose de $321,7 \mathrm{~kg}$ ha $^{-1}$ (Figura 2). Assim, o aumento da dose de $\mathrm{N}$, até determinado limite, promoveu o crescimento externo do fruto e aumento da espessura do mesocarpo e da cavidade do fruto. Em meloeiro cultivado em solo e em ambiente protegido, Coelho et al. (2003), também observaram aumento da espessura da polpa e cavidade do fruto com incremento da dose de $\mathrm{N}$ aplicado, atingindo 3,09 e 6,06 $\mathrm{cm}$ com a dose de $312 \mathrm{~kg} \mathrm{ha}^{-1} \mathrm{~N}$. Portanto, o $\mathrm{N}$ estimula o crescimento do fruto e espessura do mesocarpo, mas parece exercer efeito negativo por proporcionar aumento da cavidade do fruto.

Segundo Costa \& Pinto (1977), o fruto ideal deve ter o mesocarpo espesso e cavidade interna pequena, atributos que conferem ao fruto melhor resistência ao transporte e maior durabilidade pós-colheita. $\mathrm{O}$ aumento da cavidade do fruto pode refletir em fraca ligação da estrutura que contém as sementes e a polpa, podendo ocorrer o desprendimento das sementes e a indesejada fermentação dos frutos no manejo pós-colheita (Hartz, 1997).

As cultivares não diferiram quanto ao SST, ATT e índice de maturação (Tabela 1). Entretanto, observou-se resposta linear, crescente para SST e ATT, e decrescente para índice de maturação, com aumento da dose de N (Figura 2). Obteve-se acréscimo estimado de $1,0^{0}$ Brix no teor de SST e de $0,017 \%$ na ATT e decréscimo de 13,1 no índice de maturação entre o controle e a dose máxima de $\mathrm{N}$ aplicado.

Os valores médios de SST obtidos, nas duas cultivares, estão acima do mínimo exigido pelos importadores, que é de 9,0\% (Kader, 2002). Rizzo \& Braz (1991) observaram a existência de variabilidade entre genótipos de meloeiro, com relação ao SST e ATT, em que Bônus $\mathrm{n}^{0} 2$, Nero e Sunrise, não diferiram entre sí, no entanto, foram superiores a Aragon e Hales Best Jumbo nestas características. Maruyama et al. (2000) também observaram que 'Bônus $\mathrm{n}^{0} 2$ ' apresentou maior SST que 'D. Carlos'. Valores mais elevados de SST dos obtidos neste trabalho foram encontrados por Gualberto et al. (2001), no cultivo em solo, com média $12,9^{\circ}$ Brix, no híbrido 'Bônus $\mathrm{n}^{0} 2$ ', em diferentes sistemas de condução de plantas. Esta variação de resposta entre genótipos pode estar associada a diferentes ambientes de cultivo, principalmente em termos de temperatura e irradiância, e práticas de manejo de plantas que alteram a distribuição de assimilados entre fonte e dreno e influenciam a acumulação de açúcares no fruto do meloeiro.

Faria et al. (2000), observaram diferenças significativas no teor de SST 
do fruto do meloeiro somente na ausência de N. Purqueiro \& Cecílio Filho (2005) observaram que a concentração de $\mathrm{N}$ na solução nutritiva não alterou significativamente o teor de SST, e que o efeito benéfico do $\mathrm{N}$ sobre esta característica é mais indireto do que direto devido ao efeito do $\mathrm{N}$ sobre área foliar da planta.

Neste trabalho foi obtido comportamento semelhante ao encontrado por Purqueiro \& Cecílio Filho (2005) quanto à ATT, com aumento linear dessa com incremento da dose de N. De acordo com esses autores, esse tipo de resposta pode ser atribuído ao aumento na atividade metabólica da planta promovido pelo $\mathrm{N}$ retardando a senescência da planta, com reflexos no grau de amadurecimento dos frutos.

O índice de maturação é uma relação usada para avaliar tanto o estado de maturação quanto a palatabilidade dos frutos (Pinto et al., 1997). No presente trabalho esta não diferiu entre as cultivares (Tabela 1), porém reduziu com o aumento na dose de N (Figura 2), evidenciando que o $\mathrm{N}$ promoveu proporcionalmente, mais ATT que SST, visto que esse índice é a razão SST/ATT. Segundo Villanueva et al. (2004) no meloeiro, as modificações no sabor são devidas a alterações nos compostos aromáticos, ácidos orgânicos e açúcares solúveis. Buzetti et al. (1993) não observaram diferenças entre as cultivares de meloeiro 'Valenciano Amarelo' e 'Eldorado 300' para o índice de maturação. Considerando as doses de $\mathrm{N}$, observou-se que o índice de maturação na 'Eldorado 300' se ajustou a uma função linear crescente. Este resultado foi contrário ao obtido neste trabalho que registrou decréscimo no índice de maturação com o aumento da dose de N. Este fato, pode ser atribuído em parte à maior dose de $\mathrm{N}$ utilizada, de 540 em relação aos $200 \mathrm{~kg} \mathrm{ha}^{-1}$ usada por Buzetti, et al. (1993), que proporcionou maior valor de ATT com o aumento da dose de N, o que favoreceu a redução do índice.

\section{AGRADECIMENTOS}

Ao CNPq pela bolsa de doutorado concedida ao primeiro autor do trabalho.

\section{REFERÊNCIAS}

BUZETTI S; HERNANDEZ MESA; SUZUKI MA. 1993. Influência da adubação nitrogenada e potássica na eficiência do uso da água e na qualidade de frutos de melão. Scientia Agrícola 50: 419-426.

CARMELLO QAC. 1999. Curso de nutrição/ fertirrigação na irrigação localizada. Piracicaba: ESALQ, 59 p. (Apostilha).

COELHO EV; FONTES PCR; FINGER FL; CARDOSO AA. 2003. Qualidade do fruto de melão rendilhado em função de doses de nitrogênio. Bragantia 62: 173-178.

COELHO EV; FONTES PCR. 2005. Índices agronômicos do meloeiro associada a dose adequada de nitrogênio, em ambiente protegido e no campo. Ciência Agrotécnica 29: 974-979.

COSTA CP; PINTO CABP. 1977. Melhoramento de hortaliças. Piracicaba: ESALQ, 319 p.

EMBRAPA - Centro Nacional de Pesquisa de Solos (Rio de Janeiro, RJ). 1999. Sistema Brasileiro de Classificação de Solos - Brasília: EMBRAPA, 412p.

EMBRAPA - Embrapa Hortaliças (Brasília, DF). 2004. 15 de outubro. Utilização de tensiômetros. Disponível em http:// www.cnph.embrapa.br/.

FARIA CMB. 1990. Nutrição mineral e adubação na cultura do melão. Circular Técnica 22, EMBRAPA-CPTASA, 26p.

FARIA CMB; COSTA ND; PINTO JM; BRITO LTL; SOARES JM. 2000. Níveis de nitrogênio por fertirrigação e densidade de plantio na cultura do melão em um Vertissolo. Pesquisa Agropecuária Brasileira 35: 491-495.

GUALBERTO R; RESENDE FV; LOSASSO PHL. 2001. Produtividade e qualidade do melão rendilhado em ambiente protegido, em função do espaçamento e sistema de condução. Horticultura Brasileira 19: 373-376.

HARTZ TK. 1997. Effect of drip irrigation scheduling on muskmelon yield e quality. Scientia Horticulturae 69: 117-122.

HECKTKEUER LHR; HOLANDA LFF; GUEDES ZBL; ORIÁ HF; FIGUEIREDO RW. 1995. Características físicas e químicas do melão. Revista Brasileira de Fruticultura 17: 29-37.

HIGASHI K; HOSOYA K; EZURA H. 1999. Histological analysis of fruit development between two melon (Cucumis melo L. reticulatus) genotypes setting a different size of fruit. Journal of Experimental Botany 50: 1593-1597.
HUETT DO; DETTMANN EB. 1991. Nitrogen response surface models of zucchini squash, head lettuce and potato. Plant and Soil 134: 243-254.

KADER AA. 2002. Standardisation and inspection of flesh fruit and vegetables. In 'Postharvest Tecnology of Horticultural Crops'. (Ed. AA Kader), 287-289.

LOPES JF. 1982. Melhoramento genético (chuchu, melancia, melão e pepino). Informe Agropecuário 8: 61-65.

MARUYAMA WI; BRAZ LT; CECÍLIO FILHO AB. 2000. Condução de melão rendilhado sob cultivo protegido. Horticultura Brasileira 18: 175-179.

NERSON H; PARIS HS; EDELSTEIN M. 1992. Nitrogen and phosphorus stress repair muskmelon (Cucumis melo L.) seedlings. Journal of Plant Nutrition 10: 1835-1841.

PÁDUA JG. 2001. Cultivo protegido de melão rendilhado, em duas épocas de plantio. Jaboticabal: FCAV-UNESP, 108p (Tese doutorado).

PINTO JM; SOARES JM; COSTA ND; BRITO LTL; PEREIRA JR. 1995. Aplicação de N e K via água de irrigação em melão. Horticultura Brasileira 13: 192-195.

PINTO JM; BOTREL TA; FEITOSA FILHO JC. 1997. Efeito do nitrogênio via fertirrigação na cultura do melão. Engenharia Agrícola 16: 2735.

PURQUEIRO LFV; CECÍLIO FILHO AB; BARBOSA JC. 2003. Efeito da concentração de nitrogênio na solução nutritiva e do número de frutos por planta sobre a produção do meloeiro. Horticultura Brasileira 21: 185-190.

PURQUEIRO LFV; CECÍLIO FILHO AB. 2005. Concentração de nitrogênio na solução nutritiva e número de frutos sobre a qualidade de frutos de melão. Horticultura Brasileira 23: 831-836.

RIBEIRO AC; GUIMARÃES PTP; ALVAREZ VH. 1999. Recomendação para o uso de corretivos e fertilizantes em Minas Gerais. UFV, Viçosa-MG, 359 p.

RIZZO AN; BRAZ LT. 2001. Características de cultivares de melão rendilhado cultivadas em casa de vegetação. Horticultura Brasileira 19: 370-376.

SILVA MAG; BOARETTO AE; MELO AMT; FERNANDES HMG; SCIVITTARO W.B. 1999. Rendimento e qualidade de frutos de pimentão cultivado em ambiente protegido em função do nitrogênio e potássio aplicados em cobertura. Scientia Agrícola 56: 1199-1207.

VILLANUEVA MJ; TENORIO MD; ESTEBAN MA; MENDONZA MC. 2004. Compositional changes during ripening of two cultivars of muskmelon fruits. Food Chemistry 87: 179_ 185. 